\title{
Construction and function of the web of Tidarren sisyphoides (Araneae: Theridiidae)
}

\author{
Ruth Madrigal-Brenes and Gilbert Barrantes: Escuela de Biología, Universidad de Costa Rica, Ciudad Universitaria \\ Rodrigo Facio, San José, Costa Rica. E-mail: ruthymad@gmail.com
}

\begin{abstract}
In this paper, we describe the construction and function of the double sheet and tangle web of Tidarren sisyphoides (Walckenaer 1842). Web construction includes several stages: construction of the scaffolding that serves to support the rest of the web; filling in the dome-shaped and horizontal sheets; and construction of the upper tangle. During construction of the scaffolding, the spider descends by a pre-existing thread to the substrate, moves a few centimeters and attaches the dragline, then she ascends by the new thread, doubling the line or attaching it to another thread. The spider fills in the sheet while walking in an irregular pattern under the sheet, and attaching her dragline using either one or both legs IV simultaneously to hold pre-existing sheet lines against her spinnerets. During scaffolding construction and filling in the dome-shaped sheet, the spider returns frequently to the retreat, apparently using the same threads near the retreat each time. Threads of both the dome-shaped sheet and the horizontal sheet have small drops of viscid material. The domeshaped sheet and upper tangle comprise the functional trap of the web, while the horizontal sheet apparently plays only a little role in prey capture.
\end{abstract}

Keywords: Web-building behavior, aerial sheet web, web function, viscid threads

Web designs in Theridiidae are strikingly variable (Szlep 1965, 1966; Lamoral 1968; Eberhard 1972, 1981, 1991; Agnarsson 2004, 2005, 2006; Eberhard et al. 2008a), and similar designs have evolved independently in different genera, and in different species within a genus (Darchen \& Ledoux 1978; Eberhard 1991; Japyassú \& Jotta 2005; Barrantes \& Weng 2006a, 2007; Jörger \& Eberhard 2006; Eberhard et al. 2008a). The broad disparity in theridiid webs is possibly the result of their great flexibility in microhabitat use, their ability to adjust web design to different physical spaces, prey types, and prey availability (Turnbull 1964; Eberhard 1990a; Agnarsson \& Coddington 2007; Jörger \& Eberhard 2006; Eberhard et al. 2008b), and their response to parasitism and predation pressures (Blackledge et al. 2003; Agnarsson 2004; Barrantes et al. 2008).

Webs of theridiid spiders are sometimes described as an irregular, three-dimensional structure (Foelix 1996). However, their webs range from those that are extremely simplified as in Phoroncidia studo Levi (Eberhard 1981), with a web consisting of a single sticky line, to extremely complex, three-dimensional webs with aerial sheets, as in Achaearanea disparata Denis 1965 (Darchen \& Ledoux 1978) and Tidarren sisyphoides (Eberhard et al. 2008a). Despite the diverse array of web designs and the convergence in some of these designs, the detailed descriptions of the web-building behavior have begun to reveal some patterns in the typical behavior used to manipulate lines and in the sequence of lines laid (Benjamin \& Zschokke 2003; Jörger \& Eberhard 2006; Eberhard et al. 2008b). Knowledge of how three-dimensional webs of theridiids are built is generally fragmentary (Szlep 1965, 1966; Lamoral 1968; Benjamin \& Zschokke 2003), and limited to only a few genera.

All webs described for species within the derived genus Tidarren are tangles with aerial sheets (Agnarsson 2004; Benjamin \& Zschokke 2003; Eberhard et al. 2008a). Those of T. sisyphoides (Walckenaer 1842) (Benjamin \& Zschokke 2003) and Tidarren spp. (see Agnarsson 2004) have been described as lacking viscid threads. The sheet of $T$. sisyphoides is domeshaped, with a relatively dense tangle above it (Eberhard et al. 2008a). The spider hides in a retreat, often a curled leaf, suspended in the tangle at the peak of the dome, opening onto the underside of the dome (Eberhard et al. 2008a). Web construction behavior has never been described in Tidarren. The only report of construction of an aerial sheet web is for Achaearanea tesselata (Keyserling 1884) (Jörger \& Eberhard 2006). This study describes the web construction behavior of $T$. sisyphoides, and the function of the areas of its web.

\section{METHODS}

We observed web construction behavior of 15 adult female T. sisyphoides indoors in wire cubes $30 \mathrm{~cm}$ on a side, hanging $2 \mathrm{~m}$ above the floor from a thin fishing line. The cubes had a wire along each of the diagonals at the top, and one along one of the diagonals at the bottom. We collected the spiders with their retreats on the campus of the Universidad de Costa Rica, San Jose province $\left(9^{\circ} 54^{\prime} \mathrm{N}, 84^{\circ} 03^{\prime} \mathrm{W}\right)$, Costa Rica. We hung each retreat individually from the intersection of the two diagonal wires at the top, using silk threads (4-5 cm long) of the same web. Two spiders did not use the retreats and constructed webs without them.

We photographed twelve webs each day for several days (digital camera Olympus SP-510UZ), until each web was completed. Webs were sprayed with water just before photographing them to create a better contrast of silk threads against the cubes' backgrounds. We video recorded the complete construction of three additional webs using a Sony digital camera DCR-HC 96. Recording distance from the spider was intentionally changed during web construction to have either the entire cube in view or close-ups of different construction behaviors. We searched for sticky droplets on threads in five webs from the field. Thread samples from sheets were collected on slides framed with strips of doublesided adhesive tape, and density of viscid globules was measured following Barrantes \& Weng (2006b). We photographed viscid globules present in these threads under a compound microscope (digital camera Nikon Coolpix 4500) with a relative humidity of $60 \%$. Viscid globules were then placed in a saturated humidity chamber for $40 \mathrm{~min}$ and observed under the dissecting microscope for changes in size. 


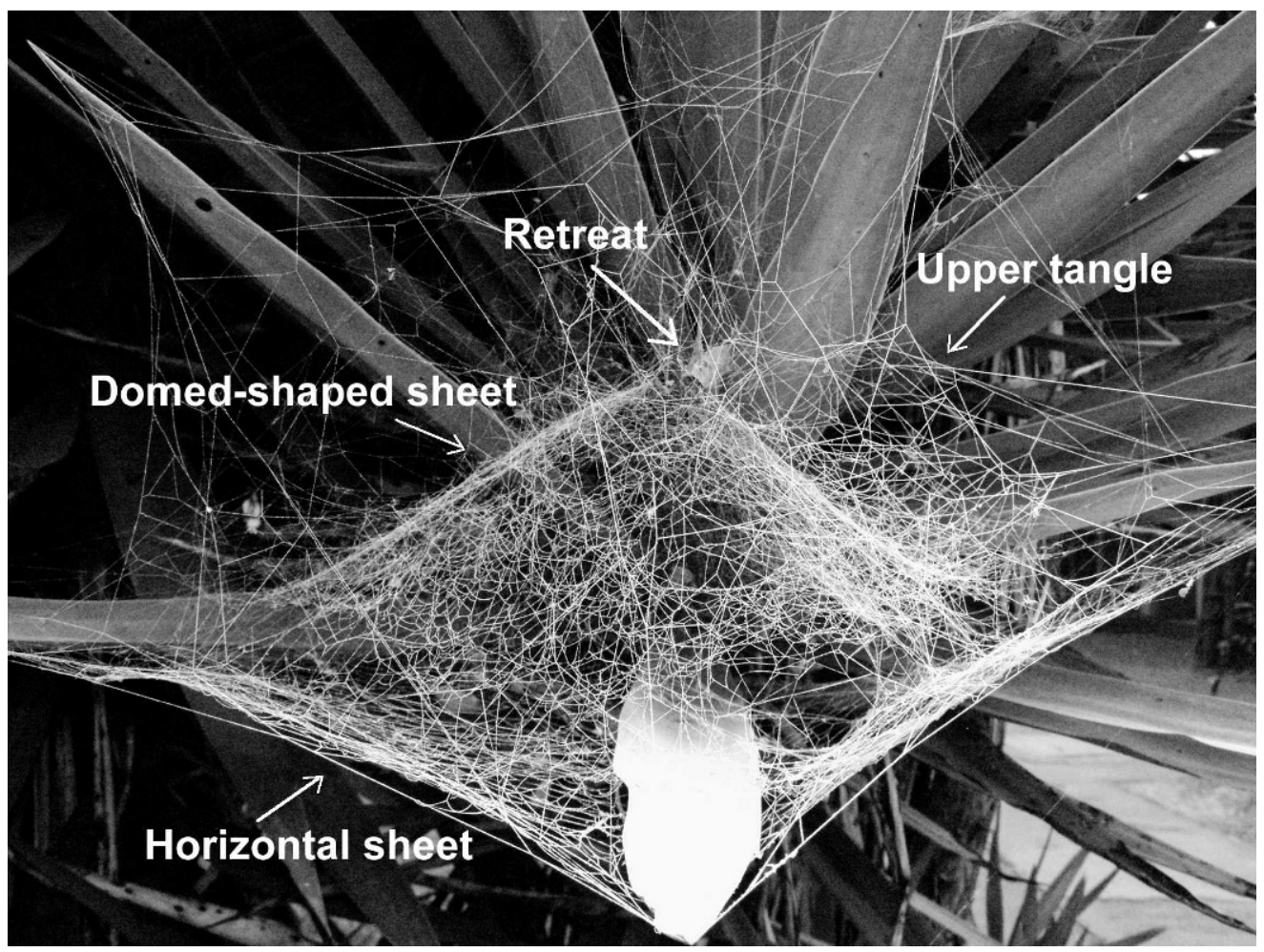

Figure 1.-Web of Tidarren sisyphoides (powdered with talcum) showing the upper tangle, the dome-shaped sheet, and the horizontal sheet.

We videotaped the attack behavior on different prey types to determine the possible function of the different sections of the web. Each spider was offered a blow fly, a moth, a grasshopper, a damselfly, a bee (Trigona spp.), a katydid, or a leaf hopper every 2 days. Some prey items were placed directly on the lower, horizontal sheet of some webs. We made additional observations of the general shape of the web, prey captured, and attack behavior of spiders in the field. Voucher specimens of the spiders were deposited in the Museo de Zoología, Universidad de Costa Rica.

\section{RESULTS}

Webs of adult spiders.-Adult females of $T$. sisyphoides constructed their webs mostly on large, solitary individuals or small groups of Agave sp., Yucca guatemalensis (Agavaceae) and Monstera deliciosa (Araceae) plants scattered over the campus. These plants all have large, relatively rigid leaves. Other plants were seldom used. The webs consisted of a large tangle in which there was a dense, upper dome-shaped sheet; a more or less horizontal, much less dense sheet at the bottom; and a retreat at the top of the dome-shaped sheet in the midst of the tangle (Fig. 1). The dome-shaped and the horizontal sheets were very loosely connected at their borders, and there was an empty space without threads under the dome in which the spider moved freely during prey capture. The dense, irregular tangle above the domeshaped sheet connected the dome to the substrates or to thick, multiple threads suspending the retreat. The border of the domeshaped sheet was also connected to the substrates nearby (wire frame, or leaves and twigs in the field). The horizontal sheet was rarely connected to leaves or other substrates ( 3 out of 23).

Web construction. $-T$. sisyphoides $(n=15)$ began construction of the web between 1730 to $1830 \mathrm{~h}$ and ended the night's work at about $530 \mathrm{~h}$ next day $(n=5)$. Spiders took from one to four nights to construct a complete, functional web, although some additional threads were certainly added subsequently. The time spent in building decreased over successive nights. The first night the spiders were nearly continually active, spinning different parts of their webs, but on subsequent nights they began later (between 21 and $23 \mathrm{~h}$ ), had longer pauses, and finished earlier (usually at 2 or $3 \mathrm{~h}$ ). The spiders' only construction-oriented diurnal activity was to secure the retreat to the wire frame soon after the retreat was first placed in the wire frame.

Web construction can be roughly divided into five different stages, some of them not being mutually exclusive: exploration, suspension of the retreat, construction of the scaffolding, construction of the dome-shaped sheet, and construction of the lower horizontal sheet. The spider walked underneath silk lines at all times during construction. She held her dragline with the tarsus of one leg IV, frequently switching the leg IV that held the dragline.

Exploration: The spider began the construction of the web by exploring the wire cube. She climbed up to the frame along the threads that secured the retreat, then walked along the horizontal and vertical wires of the frame, attaching her dragline at irregular intervals and occasionally returning to the retreat. Sometimes the spider descended beyond the wire frame, from $30 \mathrm{~cm}$ to nearly one meter, hanging from her dragline, and then climbing back up the dragline to the frame. While ascending, the spider sometimes packed the slack dragline into a mass, and a small white mass was observed near the point where she reached the frame. More frequently she did not reel up the dragline, and attached a loop, or sagging threads to the wire. Occasionally the spider descended 
a second time. All spiders but one did not descend in this way from the frame during the exploration stage. The complete exploratory phase lasted 15-30 min.

Anchoring the retreat: After exploration, the spider began to reposition the retreat. First the spider walked up the line supporting the retreat and along a horizontal wire of the upper wire frame, away from the retreat, until she reached a vertical wire. The spider then descended a few centimeters along the vertical wire and attached the thread from the retreat to the wire. The spider often reinforced this line by walking back to the retreat on the same thread, doubling it. Some of these threads were attached to the wire frame above the retreat, but others were attached to the vertical wires either at the level of the retreat or a few centimeters below it. Then the spider broke threads attached to the upper section of the retreat, causing it to drop approximately $1 \mathrm{~cm}$. This sequence was repeated several times until the retreat was moved up to nearly $10 \mathrm{~cm}$ downward from its original position, and was reoriented so that its opening was directed downward. The broken lines were occasionally packed. In these cases, the spider moved along another line while reeling up the cut line. She packed the loose line with her legs II and III, and then attached the whitish mass of silk to the wire frame or to another thread.

With the retreat in position, the spider began to spin threads from the top of the retreat to the upper wires, within the nearest $5 \mathrm{~cm}$ of the crisscrossing point of the diagonal wires. These threads were frequently reinforced by the spider walking back and forth, up to five times, on the same threads between the retreat and the furthest attaching point, forming thick cables that were clearly distinguishable from other threads. During construction of this cable, the spider was frequently observed attaching the new threads to those previously made. Construction of other sections of the web did not begin until the retreat was securely suspended from the upper section of the wire frame.

Construction of the scaffolding: Immediately after suspending the retreat, the spider began to construct the scaffolding for the dome-shaped sheet. She first spun threads that extended from the retreat opening, or near to it, to the wire frame. Additionally, she spun threads from some point along these threads to the wire frame, so that only five to six $(n=2$ webs) threads converged at (or near) the retreat opening. These threads were then interconnected, forming a roughly conical scaffolding just below the retreat.

To spin the first threads of the conical scaffolding, the spider walked along one of the threads from which the retreat was suspended and then descended by one of the vertical wires. She then either attached her dragline to the vertical wire or continued to descend to the horizontal, bottom wire frame where she attached the dragline, touching her spinnerets repeatedly on the side of the wire facing the web or on the side away from the web. Once the thread was attached, the spider ascended by the thread she just had created and attached the new thread to it, producing a double line, or else she attached the new thread to another thread she encountered on the way up, usually a few centimeters away from the retreat opening. Only rarely, this second thread was attached at the retreat opening. After some lines were present below the hub, the spider descended by a previous thread, walked 2-4 cm along the wire, attached her dragline, and ascended by this new thread. This new thread was sometimes attached to the thread
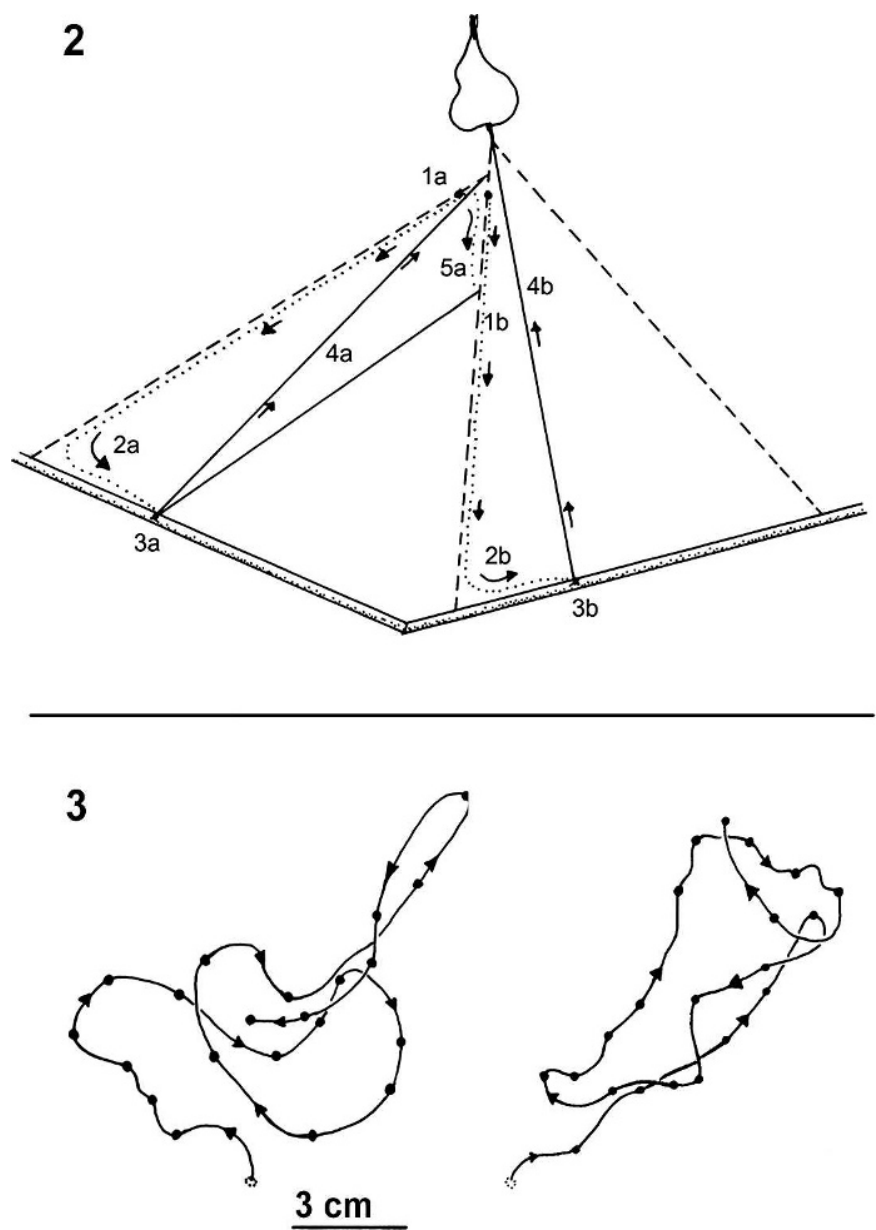

Figures 2, 3.-Behavioral sequences during web construction. 2. Placement of threads during the scaffolding construction. The numbers ( $1 \mathrm{a}-5 \mathrm{a}$ and $1 \mathrm{~b}-4 \mathrm{~b})$, arrows, and dotted lines mark the sequence and direction of movements of the spider during lines placement. Dashed lines indicate the pre-existing threads and solid lines indicate newly placed threads. 3. Two different paths of the spider as she filled in the dome-shaped sheet $(100 \mathrm{~s}$ each traced from video images recorded looking approximately perpendicular to the plane of the sheet). Black dots indicate the position of the spider every $5 \mathrm{~s}$.

she ascended, producing a double thread (Fig. 2: 1b-4b), or others to another thread (Fig. 2: 1a-5a).

When the spider had spun most lines (lines were difficult to observe and were not counted) forming the conical scaffolding, she connected these lines, and also connected them to the lines suspending the retreat. She also spun additional lines connecting the middle part of the retreat to pre-existing lines. The lines connecting the scaffolding of the dome-shaped sheet to the retreat suspension lines and to the upper section of the wire cube constituted part of the upper tangle. Video recordings showed that when attaching the dragline to another line, the spider held the dragline with one leg IV, while ipsilateral legs III and IV grasped the other line, bringing it toward the spinnerets at the same time that she bent her abdomen ventrally toward the line to touch it with her spinnerets.

Construction of the dome-shaped sheet, the horizontal sheet, and upper tangle: After the spider had constructed the scaffolding, she filled in the dome-shaped sheet. The process of filling in this sheet alternated with the construction of the 
horizontal sheet and with the upper tangle. All spiders constructed the dome-shaped sheet in two phases: first the spider wove a complete but sparse dome-shaped sheet; then she filled in the spaces in this sheet. The sparse dome-shaped sheet was constructed in the first $(n=4)$ or second night $(n=$ 11). During the second and third nights, the spiders increased the density of the dome-shaped sheet and of the threads of the upper tangle, which mostly consisted of threads connecting the dome-shaped sheet with the wires above. Construction of the horizontal sheet did not begin until the dome-shaped sheet had been partially built. The horizontal sheet was much less densely woven (Fig. 1).

The spider spent 1-3 min filling in a relatively small section of the dome-shaped sheet, then moved to a different section, sometimes on the opposite side of the dome, or sometimes nearby. After filling in a section, the spider often went up to the retreat, tapped the egg sac, then moved away to the next web section to fill in. The repeated visits to the retreat did not increase the number of threads converging at its mouth $(n=2$ webs). During the filling in activity, the spider walked under the sheet rapidly forward, and sideways in an irregular pattern (Fig. 3), while tapping actively with both legs I. We did not see individual threads in all cases, but based on the spider's behavior in video analyses, the spider did not attach her dragline to all threads she came in contact with, since she walked several millimeters and frequently several centimeters without attaching her dragline. During the dragline attachments, the spider displayed two different movements: in one, she held the dragline with one leg IV, while ipsilateral legs III and IV grasped the sheet line, and brought it toward the spinnerets; in the other, the spider's two legs IV grasped the sheet simultaneously on either side of her spinnerets while her abdomen bent ventrally toward the lines and no leg held the dragline. We clearly observed both types of attachment behaviors in the construction of both the dome-shaped and the horizontal sheets.

Most spiders had constructed the scaffolding (14 out of 15) and part of the dome-shaped sheet by the end of the first night. Only four spiders constructed a complete web during the first night. By the end of the third night, all but one spider that never constructed the horizontal sheet had complete webs. All spiders added more threads, primarily to the dome-shaped sheet and to the tangle above it in subsequent nights. Filling in the dome-shaped sheet consumed most of the construction time of the spider (about 70\%) on subsequent nights.

Viscid balls.-Viscid globules were present on threads of both the dome-shaped and the horizontal sheets in all webs examined (Fig. 4). Globules measured $58.5 \pm 30.8 \times 52.0 \pm$ $29.3 \mu \mathrm{m}(n=20$ globules, 5 webs $)$ on dome-shaped sheet lines and $100.0 \pm 62.0 \times 88.3 \pm 56.7 \mu \mathrm{m}$ on lines in the horizontal sheet ( $n=6$ globules, 2 webs). Their mean density was lower in the horizontal sheet $(0.94$ balls $/ \mathrm{mm}, \mathrm{SD}=0.62 ; 2$ webs; $26 \mathrm{~mm}$ of thread sampled) than in the dome-shaped sheet (1.5 balls $/ \mathrm{mm}, \mathrm{SD}=1.3 ; 4$ webs; $22 \mathrm{~mm}$ of thread sampled). Globules were hydrophilic and increased in size in a humidsaturated environment.

Dissecting function of the web.-In nature, seven flies in at least three different families, five treehoppers (Membracidae), two beetles (one Scarabaeidae, one Chrysomelidae) and one honey bee were found in webs $(n=22)$. Most prey that were dropped on webs were retained for several seconds in the upper

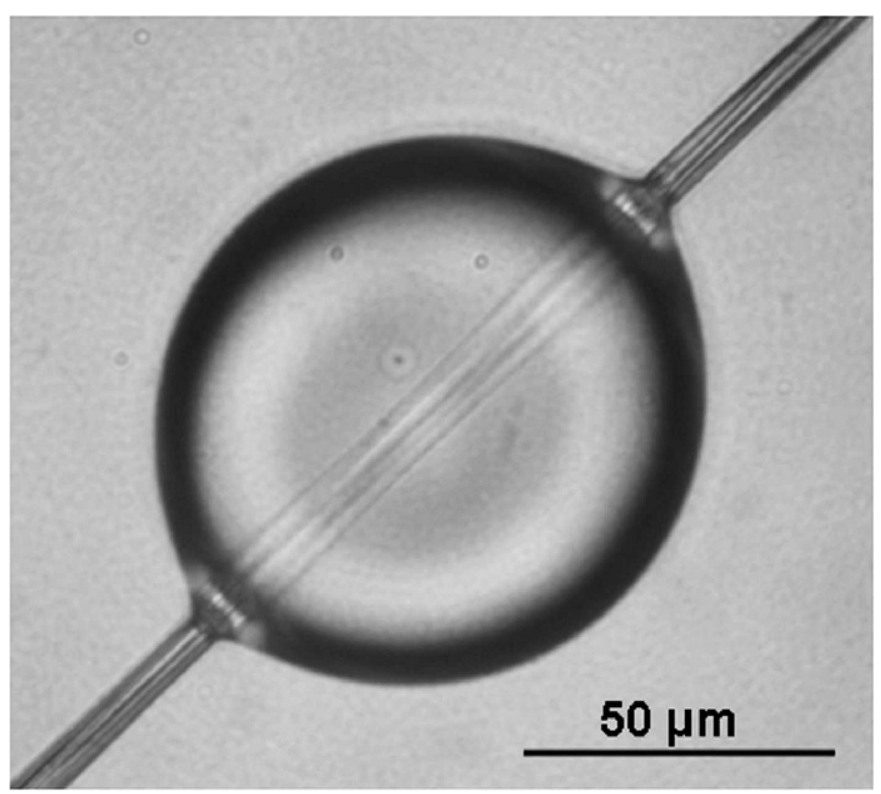

Figure 4.- Viscid globule from the dome-shaped sheet of Tidarren sisyphoides. The globule is on a pair of core fibers.

tangle (27 out of 30 ) before dropping to the dome-shaped sheet. The spider sensed the prey as soon as it contacted the upper tangle, first orienting inside her retreat (this was not possible to observe in all cases) and then moving to the area of the dome sheet beneath the struggling prey. There she pulled some threads, turned a few degrees, and pulled other threads until the prey contacted the dome-shaped sheet. On one occasion, the spider broke the threads of the dome-shaped sheet and climbed up to attack the prey in the upper tangle. Prey that fell to the dome-shaped sheet were generally constrained until the spider arrived, but in a few cases, large, strong, struggling insects (e.g., katydids) broke free from the upper tangle and dome-shaped sheet. These prey hit the horizontal sheet, but were not trapped there long enough for the spider's attack. Prey that were placed directly on the upper face of the horizontal sheet $(n=7)$ were not restrained long enough to allow the spider attack the prey.

Attack behavior.-Attacks began by applying viscid threads on to the prey with both simultaneous and alternate movements of legs IV. If the prey was dangerous (e.g., katydids), viscid threads were applied from farther away than to flies or moths. Wrapping continued until prey was immobilized, at which point it was bitten. In $83 \%$ of 72 spider-prey encounters, the spider retired to her retreat and returned to the prey after the prey's movements had subsided. When the prey was large, the spider cut it free from the domeshaped sheet before continuing the wrapping attack as it hung on a few lines below the level of the dome. If prey's movements had not completely subsided when the spider returned from her retreat, the prey was wrapped and bitten again. Then it was carried, dangling from one leg IV to near the retreat where it was wrapped some more and attached to the threads near the mouth of the retreat.

\section{DISCUSSION}

The complex aerial-sheet web of T. sisyphoides seems to be unusual in several respects among theridiids. Several other 
theridiids (e.g., Anelosimus spp., Chrosiothes portalensis, Achaearanea tesselata, A. disparata, A. japonica) also construct webs with horizontal or bowl shaped aerial-sheets (Darchen 1968; Eberhard 1972; Darchen \& Ledoux 1978; Eberhard et al. 2008a), but never a dome-shaped sheet as in $T$. sisyphoides (and also some webs of $T$. haemorrhoidale Eberhard et al. 2008a). The aerial sheets have most likely evolved independently in these theridiid lineages, as indicated by a recent phylogenetic study that showed an extremely high flexibility in web-building behaviors and high convergence in web features among theridiids (Eberhard et al. 2008a). However, the domeshaped sheet and the presence of a horizontal sheet connected to the border of the dome-shaped sheet (Fig. 1) seem to be unique features of the Tidarren genus; a horizontal sheet connected to the dome-shaped sheet has only been found in $T$. sisyphoides. The absence of similar elements in webs of other theridiid species (Agnarsson 2004; Eberhard et al. 2008a) suggests that, at least, some elements of the $T$. sisyphoides' web represent an independent and unique event in the evolution of webs in Theridiidae.

Despite the unusual design of the webs of $T$. sisyphoides, there are several general behavioral patterns in the web construction that resemble those behaviors of other theridiid species that have quite different webs. $T$. sisyphoides explored prior to initiating web construction, constructed its web only at night, constructed a scaffold that supports the rest of the web, alternated construction of different sections of the web, held its dragline with one leg IV, doubled lines during the scaffold construction, and added new threads and repaired the web over many subsequent nights. These behavior patterns are similar to those of other species of Theridiidae: Latrodectus, Steatoda, Theridion, and Achaearaea (Szlep 1965; Eberhard 1982; Benjamin \& Zschokke 2002, 2003; Jörger \& Eberhard 2006; Barrantes \& Weng 2007; Eberhard et al. 2008b), indicating that they are widespread within theridiids. Similar behaviors occur in other spider families. For instance, holding the dragline with one leg IV, alternating construction of different parts of the web, and doubling threads has also been described for other Orbiculariae (Eberhard 1990b). Descending from the retreat (or near to it) along a pre-existing thread while putting out a new line, walking on the substrate, attaching this new line to the substrate, and then ascending by this new line to return to the retreat (or near to it) during the scaffolding construction is another behavior that has also been described for Steatoda triangulosa and A. tepidariorum (Benjamin \& Zschokke 2002, 2003). This order of thread placement is similar to, though less stereotypical of, radius construction in the Nephilidae and Uloboridae (Eberhard 1982; Kuntner et al. 2008). However, further phylogenetic based studies are necessary to determine whether these behaviors are homologous between Theridiidae and other Orbiculariae.

The detailed description of web-construction by $A$. tesselata (Jörger \& Eberhard 2006), allows us to further compare the construction behavior between this species and $T$. sisyphoides. Both species strengthened the lines holding up the retreat prior to initiating construction of the web. Securing the retreat first is likely due to the fact that in both species the spiders that were observed had either egg sacs or spiderlings in their retreats; in nature, these spiders first construct a web, and then collect a curled leaf or other plant debris to construct the retreat. Attaching the anchor and scaffolding lines to the far side of objects that likely make attachments more secure, occurs also in A. tesselata and some orb-weaver araneoids (Jörger \& Eberhard 2006; Eberhard 1990b; Eberhard 2001). Breaking and releasing threads is frequent during some phases of the web construction of these two species, as well as in $S$. triangulosa (Benjamin \& Zschokke 2002) and L. geometricus (Eberhard et al. 2008b). This behavior may be at least partially explained by an inability of theridiids to digest silk, but it is also possible that loose threads might increase prey retention in the web (Kirchner 1986; Blackledge et al. 2008). Break and reel behavior was not observed in $T$. sisyphoides, though it occurs in $A$. tesselata (Jörger \& Eberhard 2006) during exploration, and in A. tepidariorum (W. Eberhard pers. comm.), and L. geometricus during gum foot line construction (Eberhard et al. 2008b).

Sheet construction by $T$. sisyphoides also resembled that of A. tesselata. The spider walked under silk lines while constructing the sheet, filling in different parts of the sheet in no apparent order (perhaps more detailed observations might establish some pattern). Attachments of the dragline were similar in both species: the spider used either one or both legs IV to hold sheet threads when she attached her dragline during filling in behavior. Both species filled in the sheet with apparently erratic wandering movements, although they were apparently more regular in $T$. sisyphoides. Both species often returned to the retreat during filling-in behavior, presumably using lines previously laid in the near vicinity of the retreat. This behavior results in only a few lines converging at the mouth of the retreat, and explains the ability of the spider to orient inside the retreat toward the prey in the web before launching an attack (Barrantes \& Weng 2006a; Jörger \& Eberhard 2006). Having few threads converging at the retreat is also a feature of newly constructed webs of several Latrodectus (Szlep 1965; Eberhard et al. 2008b).

Some general behaviors (e.g., construction of scaffolding, expansion of web over time) are widely spread within theridiids. However, some other traits such as the presence of an aerial sheet in the web have probably evolved independently several times within Theridiidae (Jörger \& Eberhard 2006; Agnarsson 2004; Eberhard et al. 2008a), and other families (e.g., Linyphiidae, Pholcidae, and SynotaxidaeChileotaxus sans) possibly as a result of using similar habitats, capturing similar prey types (Wise 1982), and predation and parasitism pressure (Blackledge et al. 2003; Agnarsson 2004).

The dome-shaped sheet and the tangle above it (upper tangle) seem to function as the trapping section of the web. The upper tangle probably functions to knock down jumping and flying insects that are then restrained by viscid elements in the dome-shaped sheet, as indicated by the insect types found in nature. The horizontal sheet at the bottom of the web seems to have little effect in prey retention; perhaps it serves as a barrier to reduce attacks of predators and parasitoids (Lubin 1986; Blackledge et al. 2003). Viscid balls have not previously been reported in webs of species in this genus (Benjamin \& Zschokke 2003; Agnarsson 2004; Eberhard et al. 2008a). The viscid balls of gum foot lines and the viscous wrapping silk in theridiids are apparently produced by the aggregate glands (Kovoor 1977; Coddington 1989). However, until the origin of the core axial fiber on which $T$. sisyphoides place the viscid balls is clearly established, it will be possible to determine 
whether these viscid threads are homologous to the gum foot lines or other sticky threads of other theridiid webs (Eberhard et al. 2008a).

\section{ACKNOWLEDGMENTS}

We thank William Eberhard for his helpful comments on the manuscript and Emilia Triana for help feeding the spiders. This study was supported by the Vicerrectoría de Investigación, Universidad de Costa Rica.

\section{LITERATURE CITED}

Agnarsson, I. 2004. Morphological phylogeny of cobweb spiders and their relatives (Araneae, Araneoidea, Theridiidae). Zoological Journal of the Linnean Society 141:447-626.

Agnarsson, I. 2005. A revision and phylogenetic analysis of the American ethicus and rupununi groups of Anelosimus (Araneae, Theridiidae). Zoologica Scripta 34:189-314.

Agnarsson, I. 2006. A revision of the New World eximius lineage of Anelosimus (Araneae, Theridiidae) and a phylogenetic analysis using worldwide exemplars. Zoological Journal of the Linnean Society 146:453-593.

Agnarsson, I. \& J.A. Coddington. 2007. Notes on web and web plasticity and description of the male of Achaearanea heiroglyphica (Mello-Leitão) (Theridiidae, Araneae). Journal of Arachnology 34:638-641.

Barrantes, G. \& J. Weng. 2006a. The attack behavior of Achaearanea tesselata (Araneae: Theridiidae). Journal of Arachnology 34:456-466.

Barrantes, G. \& J. Weng. 2006b. Viscid globules in webs of the spider Achaearanea tesselata (Araneae: Theridiidae). Journal of Arachnology 34:480-482.

Barrantes, G. \& J. Weng. 2007. The behavior and natural history of Theridion evexum (Araneae, Theridiidae). Bulletin of the British Arachnological Society 14:61-65.

Barrantes, G., W.G. Eberhard \& J. Weng. 2008. Seasonal patterns of parasitism of the tropical spiders Theridion evexum (Araneae, Theridiidae) and Allocyclosa bifurca (Araneae, Araneidae) by the wasps Zatypota petronae and Polysphincta gutfreundi (Hymenoptera, Ichneumonidae). Revista Biología Tropical 56:749-754.

Benjamin, S.P. \& S. Zschokke. 2002. Untangling the tangle-web: web construction behavior of the comb-footed spider Steadota triangulosa and comments on the phylogenetic implications (Araneae: Theridiidae). Journal of Insect Behavior 15:791-809.

Benjamin, S.P. \& S. Zschokke. 2003. Webs of theridiid spiders: construction, structure and evolution. Biological Journal of the Linnean Society 78:293-305.

Blackledge, T., J.A. Coddington \& R.G. Gillespie. 2003. Are threedimensional spider webs defensive adaptations? Ecological Letters 6:13-18.

Coddington, J.A. 1989. Spinneret silk spigot morphology: evidence for the monophyly of orbweaving spiders, and the group Theridiidae plus Nesticidae. Journal of Arachnology 17:71-95.

Darchen, R. 1968. Ethologíe d' Achaearanea disparata Denis, Aranea, Theridiidae, Araignée sociale du Gabon. Extrait de la Revue Biologia Gabonica 4:5-25.

Darchen, R. \& C. Ledoux. 1978. Achaearanea disparata, araignée sociale du Gabon, synonyme ou espèce jumelle de Achaearanea tessellata, solitaire. Revue Arachnologique 1:121-132.

Eberhard, W.G. 1972. Observations on the biology of Achaearanea tesselata (Araneae: Theridiidae). Psyche 79:209-212.
Eberhard, W.G. 1981. The single line web of Phoroncidia studo Levi (Araneae: Theridiidae): a prey attractant? Journal of Arachnology 9:229-232.

Eberhard, W.G. 1982. Behavioral characters for the higher classification of orb-weaving spiders. Evolution 36:1067-1095.

Eberhard, W.G. 1990a. Function and phylogeny of spider webs. Annual Review of Ecology and Systematics 21:341-372.

Eberhard, W.G. 1990b. Early stages of orb construction by Philoponella vicina, Leucauge mariana and Nephila clavipes (Araneae, Uloboridae and Tetragnathidae) and their phylogenetic implications. Journal of Arachnology 18:205-234.

Eberhard, W.G. 1991. Chrosiothes tonala (Araneae, Theridiidae): a web-building spider specializing on termites. Psyche 98:7-19.

Eberhard, W.G. 2001. Under the influence: webs and building behavior of Plesiometa argyra (Araneae, Tetragnathidae) when parasitized by Hymenoepimecis argyraphaga (Hymenoptera, Ichneumonidae). Journal of Arachnology 29:354-366.

Eberhard, W.G., I. Agnarsson \& H.W. Levi. 2008a. Web forms and the phylogeny of theridiid spiders (Araneae: Theridiidae): chaos from order. Systematics and Biodiversity 6:415-475.

Eberhard, W.G., G. Barrantes \& R. Madrigal-Brenes. 2008b. Vestiges of an orb-weaving ancestor? The "biogenic law" and ontogenetic changes in the webs and building behavior of the black widow spider Latrodectus geometricus (Araneae: Theridiidae). Ethology Ecology and Evolution 20:211-244.

Foelix, R.F. 1996. Biology of Spiders. Oxford University Press, New York.

Japyassú, H.F. \& E.G. Jotta. 2005. Forragemento em Achaearanea cinnabarina Levi 1963 (Araneae, Theridiidae) e evolucão da caça em aranhas de teia irregular. Biota Neotropica 5:1-15.

Jörger, K. \& W.G. Eberhard. 2006. Web construction and modification by Achaearanea tesselata (Araneae: Theridiidae). Journal of Arachnology 34:511-523.

Kirchner, W. 1986. Das Netz der Zitterspinne (Pholcus phalangioides Fuesslin) (Araneae: Pholcidae). Zoologischer Anzeiger 216:151-169.

Kovoor, J. 1977. Données histochimiques sur les glandes séricigénes de la veuve noire Latrodectus mactans Fabr. (Araneae, Theridiidae). Annales des Sciences Naturelles, Zoologie 19:63-87.

Kuntner, M., J.A. Coddington \& G. Hormiga. 2008. Phylogeny of extant nephilid orb-weaving spiders (Araneae, Nephilidae): testing morphological and ethological homologies. Cladistics 24:147-217.

Lamoral, B.H. 1968. On the nest and web structure of Latrodectus South Africa and some observations on body colouration of Latrodectus geometricus (Araneae, Theridiidae). Annals of the Natal Museum, Pietermaritzburg 20:1-14.

Lubin, Y. 1986. Web building and prey capture in the Uloboridae. Pp. 132-171. In Spiders: Webs, Behavior, and Evolution. (W.A. Shear, ed.). Stanford University Press, Stanford, California.

Szlep, R. 1965. The web-spinning process and web-structure of Latrodectus tredecimguttatus, $L$. pallidus and $L$. revivensis. Proceedings of the Zoological Society of London 145:75-89.

Szlep, R. 1966. The web structure of Latrodectus variolus Walckenaer and $L$. bishopi Kaston. Israel Journal of Zoology 15:89-94.

Turnbull, B.A. 1964. The search for prey by web-building spider Achaearanea tepidariorum (C. L. Koch) (Araneae, Theridiidae). Canadian Entomologist 96:568-579.

Wise, D.H. 1982. Spiders in Ecological Webs. Cambridge University Press, Cambridge, UK.

Manuscript received 3 March 2009, revised 21 June 2009. 